\title{
A Modern Approach For Analysis Of Manets For Dynamically Changing Network Topologies
}

\author{
S.Rajesh ${ }^{1}$, Dr.M.Sangeetha ${ }^{2}$ \\ \{rajeshsports@gmail.com ${ }^{1}$, sang_gok@yahoo.com² ${ }^{2}$ \} \\ Research Scholar, Department of Electronics and Communication Engineering, Bharath Institute of \\ Higher Education and Research Chennai, India ${ }^{1}$, \\ Professor \& Head, Department of Electronics and Communication Engineering, Bharath Institute of \\ Higher Education and Research, Chennai, India ${ }^{2}$
}

\begin{abstract}
Versatility the board is a significant test in portable impromptu organizations (MANETs) due to a limited extent to the progressively changing organization geographies. For versatile sensor network that are conveyed for reconnaissance application, critical utilize portability the executives plot that can engage hubs to settle on better choices with respect to their positions to such an extent that essential assignments, for example, target following can profit by hub development. In this paper, we portray a disseminated portability the board conspire for versatile sensor organizations. The proposed conspire considers hub development choices as a component of a disseminated advancement issue which coordinates portability upgraded improvement in the nature of target following information with the related unfortunate results of expanded energy utilization because of movement, expected deficiency of organization network, defeat of detecting inclusion..
\end{abstract}

Keywords: Mobile Adhoc Networks, Target Tracking, Mobility Management.

\section{Introduction}

Portability the executives for quite some time been perceived significant test in versatile specially appointed organizations. Versatility the board is a significant test in portable impromptu organizations (MANETs) due partially to the progressively changing organization geographies.

Versatility the board in sensor networks is not quite the same as that in versatile specially appointed organizations on the grounds that the development of sensor hubs here isn't irregular; somewhat, development of sensors hubs is deliberate, e.g., effectively and improved trail interloper.

In such situations, imperative a proficient portability the executives plan to guarantee that sensor hub versatility isexploited in the most ideal manner, e.g., to recover the nature of board following. Simultaneously, the versatility board technique ought to stay away from wasteful use of scant assets, for example, energy and organization data transfer capacity.

Besides, the portability the executives plan ought to likewise consider the expected unfortunate results of hub development, e.g., injury of territory inclusion, loss of availability, 
and corruption of organization execution. Likewise, hub development additionally includes movement liveliness and directing upstairs, particularly the essential to restore courses.

\section{Related Works}

Late exploration endeavors on track following in remote sensor networks have zeroed in on communitarian detecting energy-effective directing and the executives and sensor hub sending. Cooperative detecting and sign handling give crude tactile information low-level detecting unit sensors node[7]. By and large, modest sensors, for example, omni directional acoustic sensor utilized meanwhile choices, for example, CCD camera for the most part necessitate extra assets for control, memory, data transmission and calculation.

We center around the versatility the board issue for portable sensor networks in this task. Versatility the executives in sensor networks is not quite the same as that in portable impromptu organizations in light of the fact that the development of sensor hubs here isn't irregular; slightly, the development of sensors hubs is deliberate, e.g., to effectively and improved trajectory an interloper. In such situations, it is imperative to have a proficient portability the executives plan to guarantee that sensor hub versatility is abused in the most ideal manner, e.g., to advance the nature of objective following. Simultaneously, the portability the executives methodology ought to keep away from wasteful use of scant assets, for example, energy and organization data transfer capacity.

Directing in impromptu sensor networks has gotten a ton consideration and is viewed as an extraordinary test for specially appointed sensor organizations. Numerous endeavors have been made to accomplish energy-productive directing in information conglomeration, particularly for target following applications. The LEACH convention shapes a grouped progressive system in sensor organizations, where the bunch bonce will be liable for sending sensors information group member[9].

A portability the board system that brings together following quality, detecting inclusion, network availability, and energy utilization is presented. At last, we present a dispersed calculation for executing the proposed versatility the executives plot. 


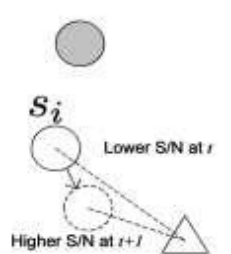

(a)

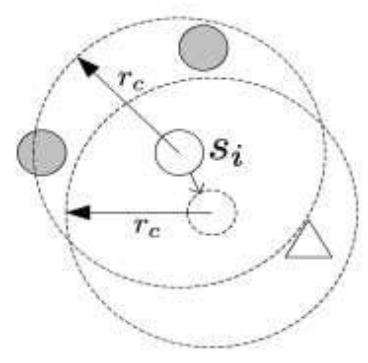

(b)

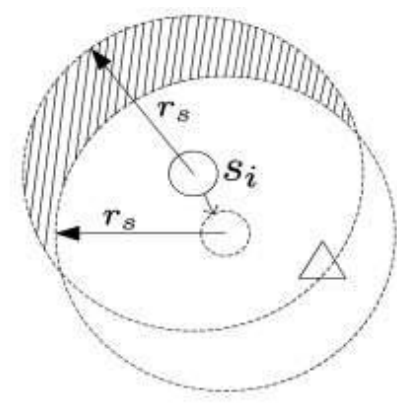

(c)

Mobile sensor node $s i$ at time $t$

One-hop neighbors of mobile sensor node $s i$ at time $t$

Mobile sensor node $s i$ at time $t+1 \rightarrow$ Mobile node $s i$ movement decision at time $t$

$\triangle$ Moving target at timet $D$ Area uncovered by si when si moves to a new location

Fig: 1(a) To recover following quality, versatile hub Si decides to move to an area that is required to have a higher sign to-clamor proportion. Fig (b) Movement of Si may break the correspondence availability with its neighbor hubs. Fig (c) Movement of Si may make some territory under inclusion at $\mathrm{t}$ time to get revealed at $\mathrm{t}+1$.

\section{Assumptions}

To rearrange the discussion [10], we variety the accompanying suppositions for the sensors organization:

1. In this articles, we accept that together sensor hubs and the objective are touching at consistent velocities.

2. We expect that the inspecting timespan sensor hubs is little enough with the end goal that there is no exceptional alteration in sensor estimations of the objective state.

3. All hubs have similar number of applicant areas where they can change.

4. A hub utilizes the earlier of its present area to foresee the sensors estimations at its upand-comer areas.

5. A hub utilizes the current sensor estimations from its present one-bounce neighbor hubs.

\section{Tracking}

To improve the nature of target following, a hub can choose to move to one more area at the following time moment. These areas are alluded to as up-and-comer areas. At that point 
define the issue of choosing the best up-and-comer area for a hub in a completely circulated way

\section{Estimates of Negative Consequences}

Evaluations of unfortunate results centers around the energy, network and inclusion issues. Hubs need to burn through extra effort for development. Despite the fact that sensor hubs on portable stages can convey more battery supplies guarantee that the accessible energy is appropriately used to best fill the need of reconnaissance assignments.

\section{Decisions on Node Movement}

Choices on hub development include the choice on hub development utilizing Cost assessment, choice on development and examination of time intricacy.

The choice standard dependent on the expense assessment that considers all adverse results because of move movement. Nodes can trade their normal absolute charge and conclude who would move. At the point when the complete expense is gotten for all applicant locations[11], the ideal choice of the up-and-comer area for hub can be acquired by thinking about together positive and unfortunate results.

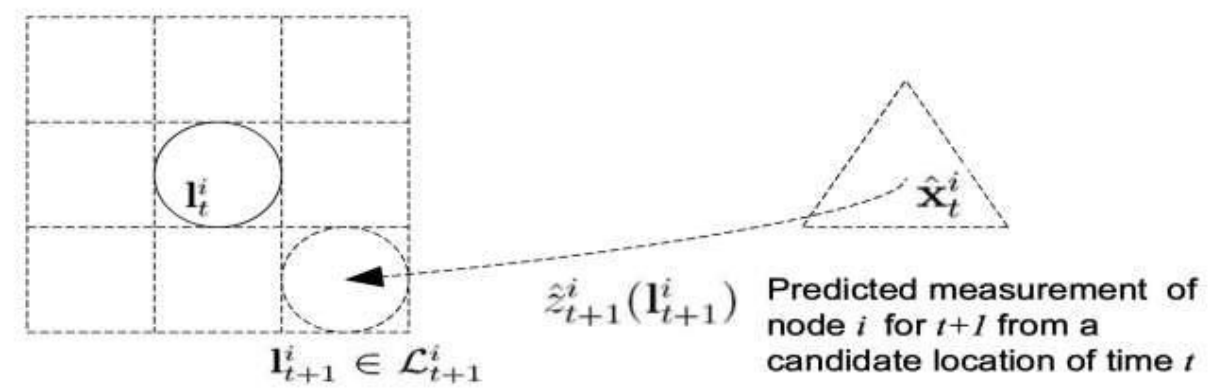

\footnotetext{
Mobile sensor node $i$ at time $t$ Target from local estimate of node $i$ Mobile sensor node $i$ at candidate location of time $t+1$
}

Fig: 2 Node Si predicts its measurement at a candidate location based on its current target estimate

\section{Simulated Studies}

7.1 Static Sensor Network versus Mobile Network with Mobility Management

The determination of the up-and-comer areas for target following information improvement depends on the hint of the mistake covariance grid. The blunder for a versatile 
sensor network is not exactly that for the still organization. Another very much acknowledged measurement for assessing the following excellence is the standard of the location mistake. The standard of the location mistake for the versatile organization is generally 72.5 percent less throughout the time that board is traveling finished the sensors arena.

The normal worldwide inclusion is characterized as the amount of separate lattice focuses finished the complete amount of network focuses. The versatility the executives conspire improves the worldwide inclusion contrasted with the static organization. Each hub can settle on its development choice in an ideal way for dynamic objective following without long arrangement with neighbors for keeping up network and sensing coverage.

\section{Results}

Every hub chooses to move to arrive at their objective by assessing the results, for example, update check, bunching speed, between grouping distance, and correspondence cost.. In view of the grouping speed, between bunching distance, update check and correspondence cost hubs choose where to change.

The outcome shows the presentation of the future method circulated versatility method. Strategy 1 in the figure aftereffect of

animal power versatility show the outcome subsequent to smearing the savage power portability in the organization.

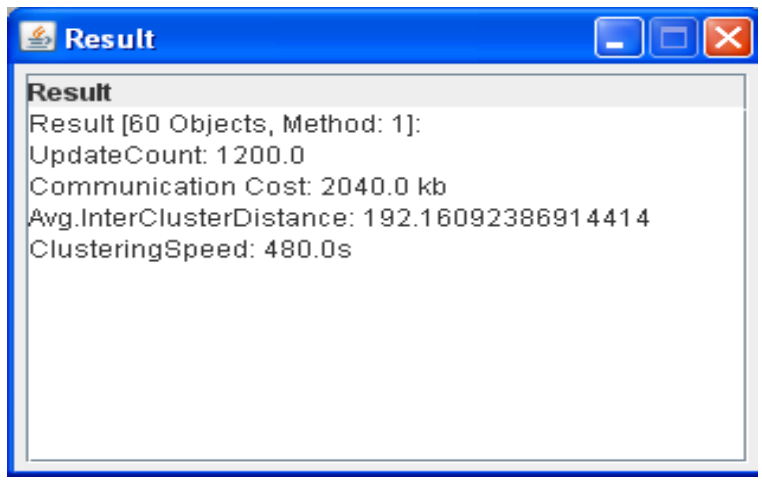

Fig:3 Result of Brute Force Mobility

Strategy 2 in the figure consequence of current appropriated portability method shows the aftereffect of current conveyed versatility method. The results show the distinction in the correspondence cost, apprise tally. Normal between grouping distance and bunching speed 


\begin{tabular}{|l|}
\hline Result \\
\hline Result [60 Objects, Method: 1 ]: \\
UpdateCount: 1200.0 \\
Communication Cost: $2040.0 \mathrm{~kb}$ \\
Avg.InterClusterDistance: 193.9453720527236 \\
ClusteringSpeed: $480.0 \mathrm{~s}$ \\
Result [60 Objects, Method: 2 ]: \\
UpdateCount: 199.0 \\
Communication Cost: $338.3 \mathrm{~kb}$ \\
Avg.InterClusterDistance: 230.56257686778358 \\
ClusteringSpeed: $79.6 \mathrm{~s}$
\end{tabular}

Fig:4 Result of Existing Distributed Mobility Approach

Technique 3 in the figure aftereffect of suggested disseminated versatility method shows the consequence of current appropriated portability method. The outcome show the distinction in the correspondence cost, update tally. Normal between grouping distance and bunching speed. Every one of the three outcomes demonstration that the future disseminated versatility method has more positive results.

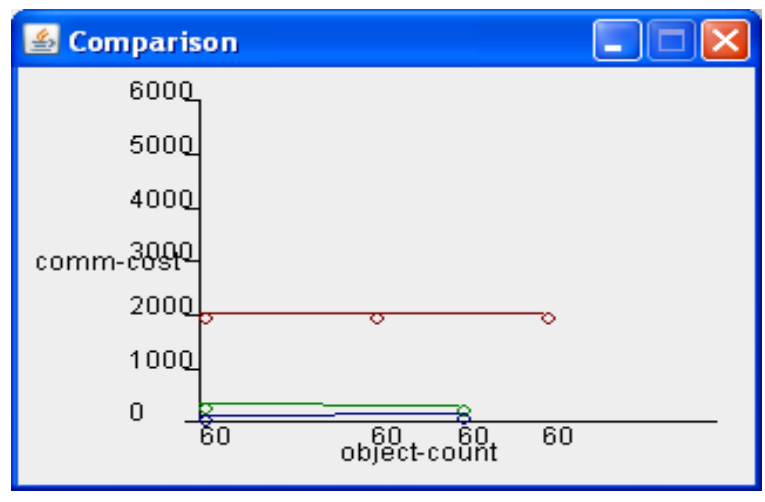

Fig:5 Comparison on Communication Cost

\begin{tabular}{|l|l|l|}
\hline Result & \\
\hline Result [60 Objects, Method: 2$]:$ & \\
UpdateCount: 199.0 & \\
Communication Cost: $338.3 \mathrm{~kb}$ \\
Avg.InterClusterDistance: 230.56257686778358 \\
ClusteringSpeed: $79.6 \mathrm{~s}$ \\
Result [60 Objects, Method: 3$]:$ \\
UpdateCount: 102.0 \\
Communication Cost: $173.4 \mathrm{~kb}$ \\
Avg.InterClusterDistance: 218.07054887706263 & \\
ClusteringSpeed: $40.8 \mathrm{~s}$ & \\
\hline
\end{tabular}

Fig: 6Result of Proposed Distributed Mobility Approach 


\section{Comparisons}

Correlations are done on the grouping speed, between bunching distance, update-check and correspondence cost. The examination on the outcomes, for example, update tally, bunching speed, between grouping distance and correspondence cost are appeared as a diagram. The examination assists with making an assessment of the exhibition of the hub development in existing framework and suggested framework just as it show how the still sensor network varies from versatile sensor organization. The outlines appeared beneath depict the adverse results between the current methodology and projected approach. It likewise depicts the improvement of the suggested approach.

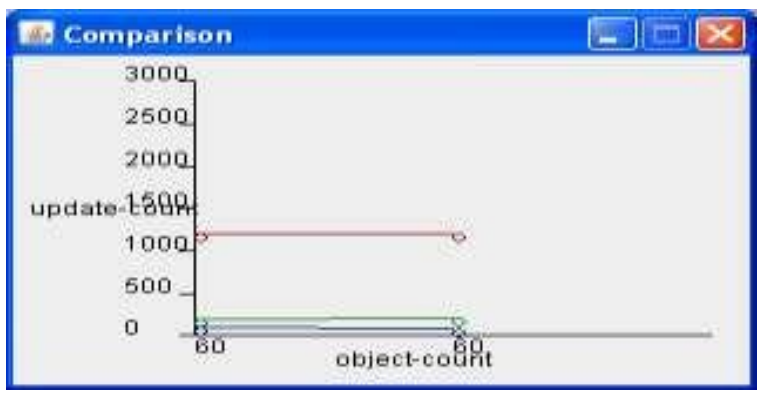

Fig:7 Comparison on Update-Count

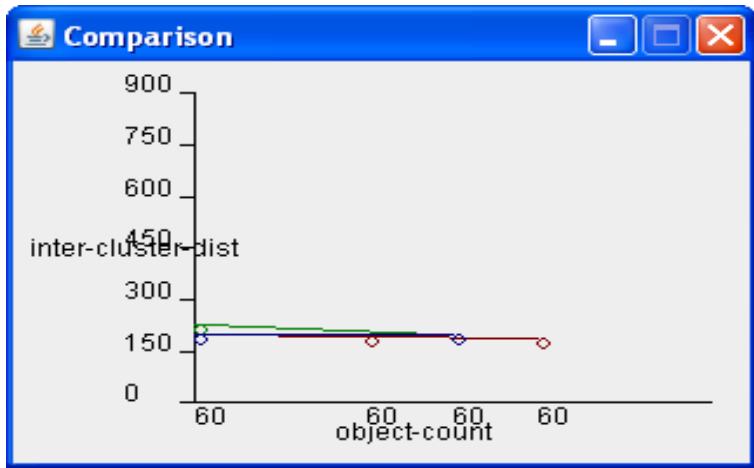

Fig:8 Comparison on Inter-Clustering Distance 


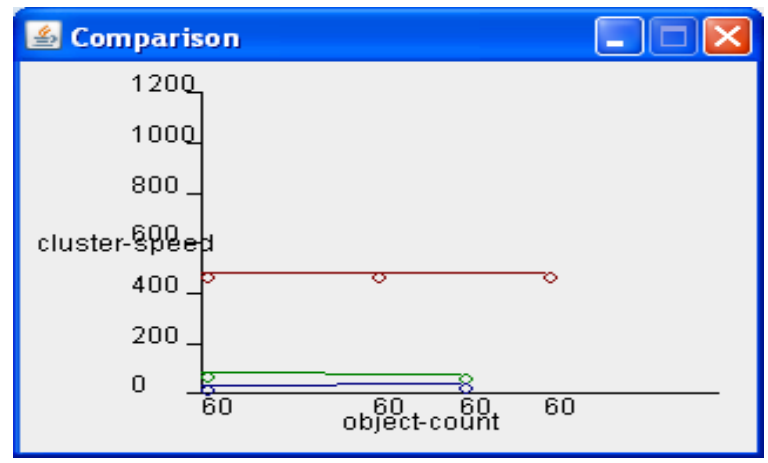

Fig:9 Comparison on Cluster Speed

\section{Conclusions}

Portability the board conspire for versatile sensors network reflects target following quality, availability breakage, and loss of detecting inclusion and energy utilization because of hub development. The continually changing geography because of hub development makes versatility the board hard for portable sensor organizations. The expense assessment strategy permits us to compromise board following excellence development with the unfortunate results of energy utilization, damage of availability and inclusion.

\section{References}

[1] Zou and Chakrabary, "Distributed Mobility Management for Target Tracking in Mobile sensor Networks," IEEE Mobile Computing, pp 872 - 887, 2007.

[2] I.F. Akyildiz, W. Su, y. Sankarasubramaniam, and E. CAyirci, "A Survey on Sensor Networks," IEEE Comm. Magazine, pp. 102-114, Aug. 2002.

[3] F.Baker, "An Outsider's view of MANET,"IETF Internet draft, work in progress, June 2006.

[4] R.R.Brooks, C.Griffin, and D.Friedlander, "Distributed Target Classification and tracking in sensor networks," proc. IEEE, pp. $1163-1171,2003$.

[5] T.Camp, J.Boleng, and V.Davies, "A Survey of Mobility Models for Ad Hoc Network Research,” J.Wireless Comm. Mobile Computing, vol.2, pp.483-502, 2002.

[6] S.S. Iyengar and R.R. Brooks, Handbook on Distributed Sensor Networks. Chapman and Hall/CRC Press, July 2003.

[7] Dr. Kaliyamurthie K.P "An Application Of Non-Uniform Cellular Automata For Efficient Cryptography", Indian Journal of Science and Technology, Vol 6, Issue 5S, page 4648-4652 May 2013.

[8] Dr. Kaliyamurthie K.P "K-Anonymity Based Privacy Preserving For Data Collection In Wireless Sensor Networks", Indian Journal of Science and Technology, Vol 6, Issue 5S, page 4604-4614 May 2013.

[9] Dr. Kaliyamurthie K.P "Highly Secured Online Voting System Over Network" , Indian Journal of Science and Technology, Vol 6, Issue 6S page 4831-4836 May 2013.

[10] Dr. Kumaravel. A "Vehnode: Wireless Sensor Network Platform For Automobile Pollution Control” IEEE explore, Vol Page(s): 963 - 966, 2013.

[11] Dr. Kumaravel. A "Multi- Classification Approach For Detecting Network" IEEE explore, Page(s): 1114 -1117,April 2013. 
[12] T. Vijayan , M. Sangeetha , A. Kumaravel \& B. Karthik (2020): FeatureSelection for Simple Color Histogram Filter based on Retinal Fundus Images for DiabeticRetinopathy Recognition, IETE Journal of Research, DOI: 10.1080/03772063.2020.1844082.

[13] D. S. Vijayan, A. Leema Rose, S. Arvindan, J. Revathy, C. Amuthadevi, “Automation systems in smart buildings: a review", Journal of Ambient Intelligence and Humanized Computing https://doi.org/10.1007/s12652-020-02666-9

[14] Vijayan T, Sangeetha M, A. Kumaravel, Karthik B, "Gabor filter and machine learning based diabetic retinopathy analysis and detection", Microprocessors and Microsystems,2020. https://doi.org/10.1016/j.micpro.2020.103353.

[15] Vijayan T, SangeethaM, Karthik B, "Trainable WEKA Segmentation of Retinal Fundus Images for Global Eye Disease Diagnosis Application," International Journal of Emerging Trends in Engineering Research,Vol 8, No.9, pp. 5750-5754, Sep 2020. https://doi.org/10.30534/ijeter/2020/136892020

[16] C. Amuthadevi, D. S. Vijayan, Varatharajan Ramachandran, "Development of air quality monitoring (AQM) models using different machine learning approaches", Journal of Ambient Intelligence and Humanized Computing, https://doi.org/10.1007/s12652-020-02724-2

[17] Vijayan T, Sangeetha M, A. Kumaravel, Karthik B, "Fine Tuned VGG19 Convolutional Neural Network Architecture for Diabetic Retinopathy Diagnosis," Indian Journal of Computer Science and Engineering (IJCSE), Vol. 11, No. 5, pp. 615-622 Sep-Oct 2020. DOI: 10.21817/indjcse/2020/v11i5/201105266.

[18] Vijayan T, Sangeetha M, Karthik B, "Efficient Analysis of Diabetic Retinopathy on Retinal Fundus Images using Deep Learning Techniques with Inception V3 Architecture,” Journal of Green Engineering, Vol 10, Issue 10, pp. 9615-9625. Oct 2020 